\title{
The Effect of Immunotherapy in Allergic Respiratory Diseases: Reappraisal of Current Knowledge
}

\section{Rita Arrigo and Nicola Scichilone}

Dipartimento Biomedico di Medicina Interna E Specialistica (DIBIMIS), Sezione di Pneumologia, University of Palermo, "Villa Sofia-Cervello" Hospital, Italy

"Corresponding author: Nicola Scichilone, Dipartimento Biomedico di Medicina Interna E Specialistica (DIBIMIS), Sezione di Pneumologia, University of Palermo, "Villa Sofia-Cervello" Hospital, via Trabucco 180, 90146 Palermo, Italy, Tel: 39-091-6802655; Fax: 39-091-6882842; E-mail: nicola.scichilone@unipa.it

Rec date: Mar 18, 2014, Acc date: Apr 22, 2014, Pub date: Apr 26, 2014

Copyright: (C) 2014 Scichilone N, et al. This is an open-access article distributed under the terms of the Creative Commons Attribution License, which permits unrestricted use, distribution, and reproduction in any medium, provided the original author and source are credited.

\begin{abstract}
Allergic rhino-conjunctivitis and asthma are induced by sensitization to one or more allergens in susceptible individuals. Specific immunotherapy (SIT) is indicated in allergic diseases, because it modulates the immune response inducing peripheral T-cell tolerance and activation of regulatory T-cells. On this basis, SIT is considered the only therapeutic approach that can modify the natural history of the allergic diseases. The development of engineered-allergen has contributed to reduce the allergenicity thus preventing the risk of side effects. The monomeric allergoids, with structural conformation and molecular size that facilitate the mucosal absorption, carry a lower risk for side effects compared to the administration of native allergens, maintaining the immunological stimulation. The efficacy of SIT, administered percutaneously (SCIT) or sublingual (SLIT), has been largely demonstrated in rhino-conjunctivitis; moreover, clinical trials have also demonstrated the efficacy of immunotherapy in allergic asthma. A therapeutic effect on asthma control has been shown in asthmatic subjects allergic to house dust mites, parietaria or grass pollen. An important and intriguing aspect of immunotherapy, not shared with the standard pharmacological treatments, is the long-lasting effect after discontinuation. In this respect, several SLIT studies in adults and children have clearly shown that the beneficial effects are maintained for up to 6 years after discontinuation of immunotherapy. The current review describes the main indications for SIT, and discusses its efficacy and safety in allergic rhino-conjunctivitis and asthma.
\end{abstract}

Keywords Rhinitis; Asthma; Vaccine; Allergen

\section{Introduction}

Allergic rhino-conjunctivitis and asthma are caused by sensitization to one or more allergens in susceptible individuals. Specific immunotherapy (SIT) is indicated in IgE-dependent allergy and represents a potentially curative treatment approach in allergic diseases. The WHO Position Paper on Allergen Immunotherapy, published in 1998 [1], proposes SIT as the only treatment that affects the natural course of allergic diseases, potentially preventing (or delaying) the development of asthma in patients with allergic rhinitis. The traditional subcutaneous immunotherapy (SCIT) has been largely demonstrated to be effective in inducing tolerance in individuals with allergic respiratory diseases. However, the risk of severe adverse events (SAE), partly related to technical or human errors, is not of little importance $[2,3]$.

The practice of administering sublingual immunotherapy (SLIT) for respiratory allergy, introduced for the first time in the mid-eighties [4] is gaining increasing diffusion worldwide based on the proved clinical efficacy and safety both in adult and in pediatric individuals with allergic rhino-conjunctivitis and/or asthma sensitized to seasonal or perennial allergens [5-8]. However, data from randomized trials comparing SLIT with SCIT are scarce, and do not seem to demonstrate significant differences between the two treatments. Similarly, indirect comparison did not provide conclusive results [9], although a more prominent effect of SCIT was found with regard to grass pollen [10]. Preliminary studies suggest that SLIT may have a role in other allergic conditions such as atopic dermatitis, food, latex and venom allergy [11].

\section{The Immunological Mechanism of Specific Immunotherapy (SIT)}

Immune responses in allergic subjects are characterized by impaired inhibitory function of allergen specific T-regulatory cells and aberrant activity of T helper type 2 (Th2) cells. The key cytokines responsible for the allergic response include IL-4, IL-13, and IL-5; these interleukins stimulate Th2 differentiation of T-naive cells and IgE production by $\mathrm{B}$ lymphocytes, which are responsible for the occurrence of symptoms after antigen re-exposure. Peripheral induction of $\mathrm{T}$ cell tolerance by allergen-specific regulatory Th1 cells is vital to healthy immune responses to allergens. The objective of SIT is the induction of immune tolerance to allergens, through changes in memory-type and allergen-specific $\mathrm{T}$ and $\mathrm{B}$ cell responses and upregulation of mast cell and basophil activation thresholds. The shift in the balance between allergen specific Th2 and T-regulatory cells is central to either development of allergen tolerance or allergic status or even the recovery from allergic disease [12-14].The T-regulatory cell stimulation by allergen causes the increased production of IL-10 and TGF- $\beta$.

IL-10 is a significant inhibitor of the allergic response, inhibiting the production, recruitment and survival of eosinophils and reducing the number of mast cells. Furthermore, IL-10 reduces the activation of allergen-specific Th2 cells, and induces suppression of IgE. In addition, IL-10 promotes the synthesis of IgG4, which is a noninflammatory isotype that protects from allergic reaction by preventing the activation of mast cells and basophils. TGF- $\beta$ is an important suppressive cytokine that is essential for the maintenance of immunologic self-tolerance; it modulates the conversion of naive 
CD4+ T cells to Treg cells, which is required for both expansion in number and suppressive capacity of Treg cells.

The aim of allergen SIT is to induce the peripheral T cell tolerance, modulate the thresholds for mast cell and basophil activation and decrease IgE-mediated histamine release. Different mechanisms are involved in rendering mast cells and basophils unresponsive to allergens even if these cells are "sensitized" by specific IgE bound to their receptor.

The described shift in immunoglobulin isotype production cannot explain the therapeutic effect of SIT. In general, the decrease in serum IgE appears much later than clinical tolerance, which occurs relatively early during the course of SIT and does not correlate with the magnitude of clinical improvement after treatment. After the first administration of SIT, a very early decrease in the susceptibility of basophils to degranulation and systemic anaphylaxis can be observed [15]. Histamine is one of the main mediators released upon triggering of basophils and mast cells, and it exerts its functions through histamine receptors (HRs) [16,17]. The release of mediators from mast cells and basophils at low levels, below the "normal" threshold of systemic anaphylaxis is probably taking place during SIT $[18,19]$. Thus, successful hyposensitization is associated with the altered magnitude of mediator release from the effector cells [18].

Efforts to develop a safer and more effective SLIT have led to the development of allergoids, recombinant allergens and formulations with adjuvants and substances targeting antigens to dendritic cells that play a crucial role in initiating the immune responses. The chemical modification of native allergens to reduce their IgE-binding activity, as shown by in vitro (immune-inhibition assays, basophil activation, and basophil mediator release) and in vivo techniques (skin testing and nasal provocation), produces hypoallergenic preparations that retain the T-cell reactivity (antigenicity), as well as the ability to induce allergen-specific IgG antibody response (immunogenicity), which are essential for the clinical effects.

The chemical modification traditionally obtained by reaction with glutaraldehyde or formaldehyde yields polymeric allergoids, with high molecular weight, suitable for injective route only. The monomeric allergoid for sublingual administration reduces the interaction with specific IgE. This leads to the enhanced tolerability of the monomeric allergoid and the potential of reducing the dose of allergen that is necessary to maintain the "therapeutic" activity. The monomeric (carbamylated) allergoids provide the structural conformation and molecular size needed to allow mucosal absorption. Preparations based on carbamylatedallergoids currently represent the only chemically modified allergens suitable for sublingual administration, inducing the tolerance induction through the stimulation of the oral mucosa-associated and gut-associated immune system with systemic absorption [11].

\section{Safety of SIT}

A large number of post-marketing studies documented the optimal safety profile, with incidence of side effects lower than $10 \%$ of treated patients with monomeric allergoids [20-22]. This high safety, in combination with high efficacy, was demonstrated in different induction (two up-dosing, one no-up-dosing) phase schedules [23] in subjects with rhino-conjunctivitis with or without asthma due to sensitization to perennial and seasonal allergens. Conversely, SLIT with native (i.e. not allergoid) allergens without up-dosing has been submitted to clinical trials to evaluate efficacy and safety, showing adverse events (mainly local) in a large percentage of treated patients $(67 \%)[10,24]$. This phenomenon is probably due to the nature of the active substance (native allergen), which maintains the ability to react with allergen-specific IgE antibodies, and consistently increases the serum concentration of these antibodies (approximately five-fold).

The potential risk of de novo sensitization to epitopes present in the vaccine theoretically exists. Some cases of neo-sensitizations have been described with SCIT; nevertheless, the risk is expected to be much lower when the allergen is delivered in an immune environment that increases tolerance induction such as the oral mucosa, as recently observed for SLIT to grass pollen and house dust mite $[25,26]$

\section{Efficacy of SIT in Allergic Rhino-Conjunctivitis}

SIT for respiratory allergy is considered complementary to the pharmacological approach for the purpose of reducing symptoms and the need for rescue medications [27]. SLIT is mainly indicated in rhino-conjunctivitis; in more than 60 positive studies (two thirds of them in dust mites and grass allergy), the magnitude of clinical effects ranged from 10 to $45 \%$ over placebo [28].

In 1998, Passalacqua and collaborators [29] demonstrated the efficacy of SLIT with monomeric allergoids derived from Dermatophagoides in patients with rhino-conjunctivitis compared with placebo group, in terms of reduction of symptoms and drug consumption after the first year of administration $(\mathrm{p}<0.05)$, which was even greater after the second year $(\mathrm{p}<0.01)$. In subjects affected by rhino-conjunctivitis treated with SLIT, a clear reduction in the allergic inflammation parameters (neutrophils, eosinophils, ICAM-1) evaluated after one and two years was demonstrated $(\mathrm{p}<0.001)$. A reduction in the eosinophil cationic protein (ECP) in the serum was also observed after both the first $(\mathrm{p}<0.01)$ and the second year $(\mathrm{p}<0.04)$ of immunotherapy. No adverse events were observed. The same authors [30] confirmed the effectiveness of SLIT with Dermatophagoides in terms of reduction of nasal obstruction, use of symptomatic medication, number of extra visits and improvement in the health-related quality of life parameters.

\section{Efficacy of SIT in Allergic Asthma}

Recent systematic review articles comparing the efficacy and safety of SLIT with those of other treatments for rhinitis and asthma have shown the superiority of immunotherapy [31,32]. However, asthma symptoms rarely represent the primary outcome [28]. Recently, a therapeutic effect on asthma control was demonstrated in asthmatic subjects allergic to house dust mites. Compared to placebo, the SLIT decreased the need of inhaled corticosteroids after one year of daily treatment [33]. A recent study investigated whether SLIT with chemically modified allergen extract provided an additional advantage in real-life settings and in a relatively long-term period, achieving the control of mild persistent asthmatic symptoms related to birch pollen [34]. Given the high tolerability of SLIT, its use in more severe forms of allergic asthma could be proposed [1]; this however needs to be addressed in specifically designed studies.

SLIT in bronchial asthma allergic to dermatophagoides pteronyssinus demonstrated to reduce the rate and severity of asthmatic attacks $(\mathrm{p}<0.001)$ and to improve lung function, by means of peak expiratory flow $(\mathrm{p}<0.001)$ [35]. A multicenter, randomized, openlabel study was conducted in children suffering from asthma with or without rhinoconjunctivitis and monosensitized to dermatophagoides. Subjects were divided in two groups, one treated with SLIT for 
dermatophagoides formulated in tablets containing the monomeric allergoid and the second with delayed-release SCIT with extracts [36]. The study confirmed the safety and efficacy of both treatments with SLIT being more indicated in young children who often do not accept the frequent injections required by SCIT. The efficacy of SLIT for graminacee in adults with rhino-conjunctivitis and asthma has also been proven in terms of reduction in both global and nasal symptoms compared to volunteers treated with placebo [37].

Patients treated with active drug also used less medications, particularly bronchodilators. These differences could already be seen after the first year of treatment, and were even more pronounced after the second year. These results were replicated in asthmatic children allergic to grass pollen [38]. Indeed, treatment with a monomeric allergoid incorporated into small tablets $(\varnothing 7 \mathrm{~mm})$ in doses of 25,100 , 300 and 1,000 UA/tablet was responsible for significantly fewer respiratory symptoms compared to the placebo group in the first year. During the second year, the active treatment group also showed a reduction in the drug consumption score. Finally, a significant reduction $(\mathrm{p}<0.01)$ in bronchial reactivity together with a significant reduction in rhinitic $(\mathrm{p}<0.001)$ and asthmatic $(\mathrm{p}<0.001)$ symptoms was observed in patients allergic to grass pollen treated with SIT compared to those receiving only symptomatic drugs [39].

In the above-cited study, the group treated with SIT demonstrated a significantly lower use of symptomatic drugs $(p<0.001)$. These findings were confirmed by La Grutta and colleagues in subjects with asthma (with or without rhinitis) who were allergic to house dust mite and Parietaria $(\mathrm{p}<0.0005)[40]$.

\section{The Long-Lasting Effect after SIT Discontinuation}

An important and intriguing aspect of immunotherapy, which is missing in conventional pharmacological treatments, is the longlasting beneficial effect after discontinuation. Several SLIT studies in adults and children show that the beneficial effects are maintained for up to 6 years after discontinuation of SLIT [41-45]. A study conducted between 1992 and 2005 evaluated the long-lasting effects of SLIT for house dust mites in allergic rhinitis with airway hyperresponsiveness [46].

Patients had been treated with the monomeric allergoid in tablets, with a standard induction phase of 14 weeks, and divided into four groups according to the duration of treatment. All patients underwent a comprehensive clinical (symptom/drug scores) and functional (lung volumes, airway hyperresponsiveness) evaluation at baseline and approximately every 2 years for the duration of the study. The main finding was the reduction in the symptom/drug scores that persisted for 8-9 years after the completion of SLIT, when this was administered for 4 years $(p<0.001$ versus baseline); shorter treatments led to less persistent effects over time, although statistically significant $(p<0.05$ versus baseline). A reduction in the degree of airway hyperresponsiveness was also observed 6-7 years after the completion of treatment $(\mathrm{p}<0.001)$.

\section{Conclusions}

Desensitization represents a potentially curative and specific approach to allergies [37]. Although SLIT and SCIT are the two main routes of administration, SLIT seems to be the more safe and favorable route of both. Several large-scaled, randomized, double-blinded, placebo-controlled trials demonstrated the long lasting and diseasemodifying effects of SLIT [47-51]. The main indication for SIT remains allergic rhino-conjunctivitis. However, a body of evidence confirms the effectiveness of SIT in allergic asthmatics in reducing airway hyperresponsiveness, symptoms and use of rescue medications. The advantages offered by SIT become evident in the long-term period, especially when compared to pharmacotherapy. The ability of SIT to modify the inflammatory response to allergens makes it the only therapeutic approach that can modify the natural history of the allergic diseases.

There is a general agreement that an appropriate use of SIT, based mainly on the techniques of molecular analysis of the antigens, may represent the complementary approach to pharmacological treatment for the optimal management of respiratory allergies. We indicate that this treatment should be primarily proposed to individuals with allergic rhino-conjunctivitis who are sensitized to a single allergen, not only to reduce the symptoms and the use of rescue medications, but also to prevent the development of bronchial asthma. The different clinical responses to treatment and in the immunological changes require further studies to identify the candidate patients to SLIT, as well as the biomarkers capable of predicting short- and long-term efficacy on the other hand.

\section{References}

1. Bousquet J, Lockey R, Malling HJ (1998) Allergen immunotherapy: therapeutic vaccines for allergic diseases. A WHO position paper. J Allergy Clin Immunol 102: 558-562.

2. Bernstein DI, Wanner M, Borish L, Liss GM (2001) Immunotherapy Committee, American Academy of Allergy, et al. (2004) Twelve-year survey of fatal reactions to allergen injections and skin testing. J Allergy Clin Immunol 113: 1129-1136.

3. Aaronson DW, Gandhi TK (2004) Incorrect allergy injections: allergists' experiences and recommendations for prevention. J Allergy Clin Immunol 113: 1117-1121.

4. Scadding GK, Brostoff J (1986) Low dose sublingual therapy in patients with allergic rhinitis due to house dust mite. Clin Allergy 16: 483-491.

5. Radulovic S, Calderon MA, Wilson D, Durham S (2010) Sublingual immunotherapy for allergic rhinitis. Cochrane Database Syst Rev 8: CD002893.

6. Calamita Z, Saconato H, Pelá AB, Atallah AN (2006) Efficacy of sublingual immunotherapy in asthma: systematic review of randomizedclinical trials using the Cochrane Collaboration method. Allergy 61: 1162-1172.

7. Penagos M, Compalati E, Tarantini F, Baena-Cagnani R, Huerta J, et al. (2006) Efficacy of sublingual immunotherapy in the treatment of allergic rhinitis in pediatric patients 3 to 18 years of age: a meta-analysis of randomized, placebo-controlled, double-blind trials. Ann Allergy Asthma Immunol 97: 141-148.

8. Penagos M, Passalacqua G, Compalati E, Baena-Cagnani CE, Orozco S, et al. (2008) Metaanalysis of the efficacy of sublingual immunotherapy in the treatment of allergic asthma in pediatric patients, 3 to 18 years of age. Chest 133: 599-609.

9. Dretzke J, Meadows A, Novielli N, Huissoon A, Fry-Smith A, et al. (2013) Subcutaneous and sublingual immunotherapy for seasonal allergic rhinitis: a systematic review and indirect comparison. J Allergy Clin Immunol 131: 1361-1366.

10. Di Bona D, Plaia A, Leto-Barone MS, La Piana S, Di Lorenzo G (2012) Efficacy of subcutaneous and sublingual immunotherapy with grass allergens for seasonal allergic rhinitis: a meta-analysis-based comparison. J Allergy Clin Immunol 130: 1097-1107.

11. Compalati E, Braido F, Walter Canonica G (2013) Sublingual immunotherapy: recent advances. Allergol Int 62: 415-423. 
12. Meiler F, Zumkehr J, Klunker S, Rückert B, Akdis CA, et al. (2008) In vivo switch to IL-10-secreting $\mathrm{T}$ regulatory cells in high dose allergen exposure. J Exp Med 205: 2887-2898.

13. Akdis M, Verhagen J, Taylor A, Karamloo F, Karagiannidis C, et al. (2004) Immune responses in healthy and allergic individuals are characterized by a fine balance between allergen-specific $\mathrm{T}$ regulatory 1 and T helper 2 cells. J Exp Med 199: 1567-1575.

14. Möbs C, Ipsen H, Mayer L, Slotosch C, Petersen A, et al. (2012) Birch pollen immunotherapy results in long-term loss of Bet v 1-specific TH2 responses, transient TR1 activation, and synthesis of IgE-blocking antibodies. J Allergy Clin Immunol 130: 1108-1116.

15. Jutel M, Müller UR, Fricker M, Rihs S, Pichler WJ, et al. (1996) Influence of bee venom immunotherapy on degranulation and leukotriene generation in human blood basophils. Clin Exp Allergy 26: 1112-1118.

16. Jutel M, Akdis M, Akdis CA (2009) Histamine, histamine receptors and their role in immune pathology. Clin Exp Allergy 39: 1786-1800.

17. O'Mahony L, Akdis M, Akdis CA (2011) Regulation of the immune response and inflammation by histamine and histamine receptors. J Allergy Clin Immunol 128: 1153-1162.

18. Eberlein-König B, Ullmann S, Thomas P, Przybilla B (1995) Tryptase and histamine release due to a sting challenge in bee venom allergic patients treated successfully or unsuccessfully with hyposensitization. Clin Exp Allergy 25: 704-712.

19. Plewako H, Wosiska K, Arvidsson M, Bjorkander J, Skov PS, et al. (2006) Basophil interleukin 4 and interleukin 13 production is suppressed during the early phase of rush immunotherapy. Int Arch Allergy Immunol 141: 346-353.

20. Lombardi C, Gargioni S, Melchiorre A, Tiri A, Falagiani P, et al. (2001) Safety of sublingual immunotherapy with monomeric allergoid in adults: multicenter post-marketing surveillance study. Allergy 56: 989-992.

21. Agostinis F, Tellarini L, Canonica GW, Falagiani P, Passalacqua G (2005) Safety of sublingual immunotherapy with a monomeric allergoid in very young children. Allergy 60: 133 .

22. Agostinis F, Foglia C, Bruno ME, Falagiani P (2009) Efficacy, safety and tolerability of sublingual monomeric allergoid in tablets given without up-dosing to pediatric patients with allergic rhinitis and/or asthma due to grass pollen. Eur Ann Allergy Clin Immunol 41: 177-180.

23. Passali D, Mösges R, Passali GC, Passali FM, Ayoko G, et al. (2010) Safety, tolerability and efficacy of sublingual allergoid immunotherapy with three different shortened up-dosing administration schedules. Acta Otorhinolaryngol Ital 30: 131-137.

24. Cox L, Compalati E, Kundig T, Larche M (2013) New directions in immunotherapy. Curr Allergy Asthma Rep 13: 178-195.

25. Baron-Bodo V, Batard T, Nguyen H, Fréreux M, Horiot S, et al. (2012) Absence of IgE neosensitization in house dust mite allergic patient following sublingual immunotherapy. Clin Exp Allergy 42: 1510-1518.

26. Marcucci F, Sensi L, Incorvaia C, Dell'Albani I, Di Cara G, et al. (2012) Specific IgE response to different grass pollen allergen components in children undergoing sublingual immunotherapy. Clin Mol Allergy 10: 7.

27. Bousquet J, Van Cauwenberge P, Khaltaev N; Aria Workshop Group; World Health Organization (2001) Allergic rhinitis and its impact on asthma. J Allergy Clin Immunol 108: S147-334.

28. Canonica GW, Bousquet J, Casale T, Lockey RF, Baena-Cagnani CE, et al. (2009) Sub-lingual immunotherapy: World Allergy Organization Position Paper. Allergy 64: 1-59.

29. Passalacqua G, Albano M, Fregonese L, Riccio A, Pronzato C, et al. (1998) Randomised controlled trial of local allergoid immunotherapy on allergic inflammation in mite-induced rhinoconjunctivitis. Lancet 351: 629-632.

30. Passalacqua G, Pasquali M, Ariano R, Lombardi C, Giardini A, et al (2006) Randomized double-blind controlled study with sublingual carbamylatedallergoid immunotherapy in mild rhinitis due to mites. Allergy 61: 849-854.

31. Lin SY, Erekosima N, Kim JM, Ramanathan M, Suarez-Cuervo C, et al. (2013) Sublingual immunotherapy for the treatment of allergic rhinoconjunctivitis and asthma: a systematic review. JAMA 309: 1278-1288.

32. Kim JM, Lin SY, Suarez-Cuervo C, Chelladurai Y, Ramanathan M, et al. (2013) Allergen-specific immunotherapy for pediatric asthma and rhinoconjunctivitis: a systematic review. Pediatrics 131: 1155-1167.

33. Mosbech H (2011) Tolerability and efficacy of house dust mite AIT. Allergy 66: 55-56.

34. Marogna M, Braidi C, Bruno ME, Colombo C, Colombo F, et al. (2013) The contribution of sublingual immunotherapy to the achievement of control in birch-related mild persistent asthma: a real-life randomised trial. Allergol Immunopathol (Madr) 41: 216-224.

35. Pacor ML, Biasi D, Carletto A, Lunardi C (1995) [Effectiveness of oral immunotherapy in bronchial asthma caused by Dermatophagoidespternyssinus]. Recenti Prog Med 86: 489-491.

36. La Rosa M, Ranno C, Guglielmo F, Capristo M (1996) Clinical experience on sublingual immunotherapy with monomeric allergoids extracts of Dermatophagoides in childhood with respiratory allergy. Notiziario Allergologico 15: 45-46

37. Bordignon V, Di Berardino L (1994) Effictiveness of a new form of orally-absorbed immunotherapy for grass pollen allergy: a three-year parallel study. Giorn It Allergol Immunol 4: 153-159

38. Cavagni G (1996) Sublingual grass immunotherapy in children. A controlled trial against placebo. NotiziarioAllergologico 15: 37-39

39. Lombardi C, Gargioni S, Venturi S, Zoccali P, Canonica GW, et al. (2001) Controlled study of preseasonal immunotherapy with grass pollen extract in tablets: effect on bronchial hyperreactivity. J Investig Allergol Clin Immunol 11: 41-45,

40. La Grutta S, Arena A, D'Anneo WR, Gammeri E, Leonardi S, et al. (2007) Evaluation of the anti inflammatory and clinical effects of sublingual immunotherapy with carbamylated allergoid in allergic asthma with or without rhinitis. A 12-month perspective randomized, controlled, trial. Eur Ann Allergy Clin Immunol 39: 40-44.

41. Didier A, Worm M, Horak F, Sussman G, de Beaumont O, et al. (2011) Sustained 3-year efficacy of pre- and coseasonal 5-grass-pollen sublingual immunotherapy tablets in patients with grass pollen-induced rhinoconjunctivitis. J Allergy Clin Immunol 128: 559-566.

42. Durham SR, Emminger W, Kapp A, Colombo G, de Monchy JG, et al. (2010) Long-term clinical efficacy in grass pollen-induced rhinoconjunctivitis after treatment with SQ-standardized grass allergy immunotherapy tablet. J Allergy Clin Immunol 125: 131-138.

43. Marogna M, Spadolini I, Massolo A, Canonica GW, Passalacqua G (2010) Long-lasting effects of sublingual immunotherapy according to its duration: a 15-year prospective study. J Allergy Clin Immunol 126: 969-975.

44. Di Rienzo V, Marcucci F, Puccinelli P, Parmiani S, Frati F, et al. (2003) Long-lasting effect of sublingual immunotherapy in children with asthma due to house dust mite: a 10-year prospective study. Clin Exp Allergy 33: 206-210.

45. Tahamiler R, Saritzali G, Canakcioglu S (2007) Long-term efficacy of sublingual immunotherapy in patients with perennial rhinitis. Laryngoscope 117: 965-969.

46. Marogna M, Bruno M, Massolo A, Falagiani P (2007) Long-lasting effects of sublingual immunotherapy for house dust mites in allergic rhinitis with bronchial hyperreactivity: A long-term (13-year) retrospective study in real life. Int Arch Allergy Immunol 142: 70-78.

47. Amar SM, Harbeck RJ, Sills M, Silveira LJ, O'Brien H, et al. (2009) Response to sublingual immunotherapy with grass pollen extract: monotherapy versus combination in a multiallergen extract. J Allergy Clin Immunol 124: 150-156.

48. Bufe A, Eberle P, Franke-Beckmann E, Funck J, Kimmig M, et al. (2009) Safety and efficacy in children of an SQ-standardized grass allergen tablet for sublingual immunotherapy. J Allergy Clin Immunol 123: 167-173.

49. Durham SR, Emminger W, Kapp A, Colombo G, de Monchy JG, et al. (2010) Long-term clinical efficacy in grass pollen-induced rhinoconjunctivitis after treatment with SQ-standardized grass allergy immunotherapy tablet. J Allergy Clin Immunol 125: 131-138. 
Citation: Arrigo R and Scichilone N (2014) The Effect of Immunotherapy in Allergic Respiratory Diseases: Reappraisal of Current Knowledge. J Allergy Ther 5: 171. doi:10.4172/2155-6121.1000171

Page 5 of 5

50. Horak F, Zieglmayer P, Zieglmayer R, Lemell P, Devillier P, et al. (2009) Early onset of action of a 5-grass-pollen 300-IR sublingual immunotherapy tablet evaluated in an allergen challenge chamber. J Allergy Clin Immunol 124: 471-477, 477.
51. Skoner D, Gentile D, Bush R, Fasano MB, McLaughlin A, et al. (2010) Sublingual immunotherapy in patients with allergic rhinoconjunctivitis caused by ragweed pollen. J Allergy Clin Immunol 125: 660-666.

This article was originally published in a special issue, entitled: "Asthma",

Edited by Manar A Nader, Mansoura University, Egypt 